NBER WORKING PAPER SERIES

\title{
THE LOSS AVERSION / NARROW FRAMING APPROACH TO THE EQUITY PREMIUM PUZZLE
}

\author{
Nicholas Barberis \\ Ming Huang \\ Working Paper 12378 \\ http://www.nber.org/papers/w12378 \\ NATIONAL BUREAU OF ECONOMIC RESEARCH \\ 1050 Massachusetts Avenue \\ Cambridge, MA 02138 \\ July 2006
}

This essay will appear in the Handbook of Investments: Equity Premium, edited by Rajnish Mehra. We thank Raj Mehra for inviting us to contribute a chapter, and are grateful to him and to participants in the " $20^{\text {th }}$ Anniversary of the Equity Premium" conference in Santa Barbara, California, for valuable feedback. Comments are welcome at nick.barberis@yale.edu and mh375@cornell.edu. The views expressed herein are those of the author(s) and do not necessarily reflect the views of the National Bureau of Economic Research.

(C2006 by Nicholas Barberis and Ming Huang. All rights reserved. Short sections of text, not to exceed two paragraphs, may be quoted without explicit permission provided that full credit, including $\odot$ notice, is given to the source. 
The Loss Aversion / Narrow Framing Approach to the Equity Premium Puzzle

Nicholas Barberis and Ming Huang

NBER Working Paper No. 12378

July 2006

JEL No. G11, G12

\begin{abstract}
$\underline{\text { ABSTRACT }}$
We review a recent approach to understanding the equity premium puzzle. The key elements of this approach are loss aversion and narrow framing, two well-known features of decision-making under risk in experimental settings. In equilibrium, models that incorporate these ideas can generate a large equity premium and a low and stable risk-free rate, even when consumption growth is smooth and only weakly correlated with the stock market. Moreover, they can do so for parameter values that correspond to sensible attitudes to independent monetary gambles. We conclude by suggesting some possible directions for future research.
\end{abstract}

Nicholas C. Barberis

Yale School of Management

135 Prospect Street PO Box 208200

New Haven CT 06520-8200

and NBER

nick.barberis@yale.edu

Ming Huang

319 Sage Hall

Johnson School of Management

Cornell University

Ithaca, NY 14853

mh375@cornell.edu 


\section{Introduction}

One of the best-known stock market puzzles is the equity premium puzzle, which asks why stocks historically earned a higher average return, relative to T-Bills, than seems justified by standard measures of risk (Mehra and Prescott, 1985). In this essay, we discuss a recent approach to addressing this puzzle. The broad theme of this approach is that we may be able to improve our understanding of how people evaluate stock market risk, and hence our understanding of the equity premium, by looking at how people evaluate risk in experimental settings. Specifically, this approach argues that loss aversion and narrow framing, two of the most important ideas to emerge from the experimental literature on decision-making under risk, may play an important role in the way some people think about the stock market.

Loss aversion is a central feature of Kahneman and Tversky's (1979) prospect theory a descriptive theory, based on extensive experimental evidence, of how people evaluate risk. In this theory, the carriers of value are not absolute levels of wealth, but rather, gains and losses measured relative to a reference point. Loss aversion is the finding that people are much more sensitive to losses - even small losses - than to gains of the same magnitude.

To understand narrow framing, recall that under traditional utility functions defined over consumption or total wealth, the agent evaluates a new gamble by first mixing it with the other risks he is already facing and then checking whether the combination is attractive. Narrow framing, by contrast, is the phenomenon documented in experimental settings whereby, when people are offered a new gamble, they sometimes evaluate it in isolation, separately from their other risks. In other words, they act as if they get utility directly from the outcome of the gamble, even if the gamble is just one of many that determine their overall wealth risk. This behavior is at odds with traditional utility functions, under which the agent only gets utility from the outcome of a new gamble indirectly, via its contribution to his total wealth.

Motivated by these ideas, some recent papers propose that people are loss averse over changes in the value of their stock market holdings. In other words, even if stock market risk is just one of many risks that determine their overall wealth risk - others being labor income risk and housing risk, say - people still get utility directly from stock market fluctuations (narrow framing) and are more sensitive to losses than to gains (loss aversion). For reasons we discuss below, most implementations also assume that people focus on annual gains and losses. Informally, then, people evaluate stock market risk by saying: "Well, stocks could go up over the next year, and that would feel good; but they could also go down, and since I'm more sensitive to losses than to gains, that would be really painful. Overall, the stock market doesn't look like an attractive risk to me." According to the approach we describe in this essay, it is this sort of thinking that leads the investing population to demand a high equity premium. 
Why should economists be interested in this particular approach to the equity premium puzzle? What are its selling points? In this survey, we emphasize two. First, a model that incorporates loss aversion and narrow framing can generate a high equity premium while also matching other aspects of the data, such as the low and stable risk-free rate, the low volatility of consumption growth, and the low correlation of stock returns and consumption growth. With some additional structure, it can also match the high volatility and time-series predictability of stock returns.

A second benefit of the framework described here is that it can address the equity premium puzzle for preference parameters that are "reasonable," by which we mean parameters that correspond to sensible attitudes to independent monetary gambles. This is important because it was, in part, the difficulty researchers encountered in reconciling the high average return on stocks with reasonable attitudes to large-scale monetary gambles that launched the equity premium literature in the first place.

The approach we survey here was first proposed by Benartzi and Thaler (1995). In their framework, the investor is loss averse over fluctuations in the value of his financial wealth, which, since financial wealth is just one component of total wealth, constitutes narrow framing. One drawback of this framework is that, since the investor gets no direct utility at all from consumption or total wealth, consumption plays no role, making it hard to check how well the model describes the joint properties of stock returns and consumption growth.

Benartzi and Thaler's work therefore opens up a new challenge: to build and evaluate more realistic models in which, even if the investor gets utility from fluctuations in the value of one component of his wealth, he also gets some utility from consumption. In large part, this essay surveys the progress that has been made on this front, drawing primarily on the analysis of Barberis, Huang, and Santos (2001) and Barberis and Huang (2004).

The story we tell in this essay is a simple one: investors require a high equity premium because any drop in the stock market over the next year will bring them direct disutility. To some readers, this story may be too simple, in that the distance between assumption and conclusion may appear too close for comfort. We are aware of this concern and agree that if the loss aversion / narrow framing framework is to gain currency, its predictions must be tested and confirmed. Fortunately, tests of the framework are starting to appear, and we discuss some of them at the end of the essay. Even before the outcome of these tests is known, however, there is a methodological contribution in the research surveyed here that even a skeptical reader can appreciate: the papers we discuss show how loss aversion and narrow framing can be incorporated into more traditional models of asset pricing, thereby helping us understand the predictions of these features of decision-making.

In Section 2, we discuss loss aversion and narrow framing in more detail, examining both 
the evidence they are inferred from and the interpretations they are given. In Section 3, we show that, once embedded into more traditional utility functions, these features can generate a high equity premium and a low and stable risk-free rate, even when consumption growth is smooth and only weakly correlated with stock returns; and moreover, that they can do so for parameter values that correspond to sensible attitudes to both large-scale and smallscale monetary gambles. We highlight the importance of the narrow framing assumption by showing that, without this feature, the results are very different. In Section 4, we note that the analysis also has implications for a portfolio puzzle, the stock market participation puzzle. Section 5 considers various extensions of the basic framework, while Section 6 concludes and discusses possible directions for future research.

Since loss aversion and narrow framing are the defining features of the approach we describe here, the framework should, strictly speaking, be called the "loss aversion and narrow framing" approach to the equity premium puzzle. Given that narrow framing is the more distinctive of the two ingredients, we sometimes abbreviate this to the "narrow framing" approach. ${ }^{1}$

\section{Loss Aversion and Narrow Framing}

Loss aversion is a central feature of Kahneman and Tversky's (1979) prospect theory, a prominent descriptive theory of decision-making under risk. In this theory, the carriers of value are not absolute wealth levels, but rather, gains and losses measured relative to a reference point. Loss aversion is a greater sensitivity to losses - even small losses - than to gains of the same magnitude, and is represented by a kink in the utility function.

The most basic evidence for loss aversion is the fact that people tend to reject gambles of the form

$$
\left(110, \frac{1}{2} ;-100, \frac{1}{2}\right)
$$

to be read as "win $\$ 110$ with probability $\frac{1}{2}$, lose $\$ 100$ with probability $\frac{1}{2}$, independent of other risks" (Kahneman and Tversky, 1979, Tversky and Kahneman, 1992). It is hard to explain this evidence with differentiable utility functions, whether expected utility or nonexpected utility, because the very high local risk aversion required to do so typically predicts an implausibly high level of aversion to large-scale gambles (Epstein and Zin, 1990, Rabin, 2000, Barberis, Huang, and Thaler, 2006). ${ }^{2}$

\footnotetext{
${ }^{1}$ Benartzi and Thaler (1995) use the label "myopic loss aversion". By using this phrase, they emphasize the investor's sensitivity to losses (loss aversion) and his focus on annual gains and losses (myopia), but not the narrow framing. As we will see, narrow framing is more crucial to the results than the annual evaluation of gains and losses. We therefore prefer to emphasize the narrow framing while playing down the myopia.

${ }^{2}$ There is also strong evidence of what Thaler (1980) calls an "endowment effect," which can be thought
} 
For reasons of tractability, the asset pricing models we describe later do not incorporate all features of prospect theory. However, even if it were possible to solve a dynamic asset pricing model that did incorporate all of prospect theory's features, we would not expect the implications for the equity premium to be very different. Under prospect theory, attitudes to a gamble like the stock market, which entails a moderate probability of a gain or of a loss, are largely determined by loss aversion alone. ${ }^{3}$

The classic demonstration of narrow framing is due to Tversky and Kahneman (1981), who ask 150 subjects the following question:

Imagine that you face the following pair of concurrent decisions. First examine both decisions, then indicate the options you prefer:

Choice (I) Choose between:

A. a sure gain of $\$ 240$

B. $25 \%$ chance to gain $\$ 1,000$ and $75 \%$ chance to gain nothing

Choice (II) Choose between:

C. a sure loss of $\$ 750$

D. $75 \%$ chance to lose $\$ 1,000$ and $25 \%$ chance to lose nothing.

Tversky and Kahneman (1981) report that $84 \%$ of subjects chose A, with only $16 \%$ choosing $\mathrm{B}$, and that $87 \%$ chose $\mathrm{D}$, with only $13 \%$ choosing $\mathrm{C}$. In particular, $73 \%$ of subjects chose the combination A\&D, namely

$25 \%$ chance to win $\$ 240, \quad 75 \%$ chance to lose $\$ 760$,

which is surprising, given that this choice is dominated by the combination B\&C, namely

$25 \%$ chance to win $\$ 250, \quad 75 \%$ chance to lose $\$ 750$.

It appears that instead of focussing on the combined outcome of decisions I and II - in other words, on the outcome that determines their final wealth - subjects are focussing on the

of as loss aversion in the absence of uncertainty. Kahneman, Knetsch, and Thaler (1990) conduct a series of experiments in which subjects are either given some object such as a coffee mug and then asked if they would be willing to sell it, or not given a mug and then offered the chance to buy one. The authors find that mug owners demand more than twice as much to sell their mugs as non-owners are willing to pay to acquire one.

${ }^{3}$ The asset pricing implications of other features of prospect theory are studied, in simple settings, by Barberis and Huang (2005), who focus on the probability weighting function; and by Barberis and Xiong (2005) and Gomes (2005), who focus on the concavity (convexity) of the value function over gains (losses). 
outcome of each decision separately. Indeed, subjects who are asked only about decision I do overwhelmingly choose A; and subjects asked only about decision II do overwhelmingly choose D.

In more formal terms, it appears that we cannot model the typical subject as maximizing a utility function defined only over total wealth. Rather, his utility function appears to depend directly on the outcome of each of decisions I and II, rather than just indirectly, via the contribution of each decision to overall wealth. As such, this is an example of narrow framing.

More recently, Barberis, Huang, and Thaler (2006) have argued that the commonly observed rejection of the gamble in (1) is not only evidence of loss aversion, but of narrow framing as well. To see why, note that most of the subjects who are offered this gamble are typically already facing other kinds of risk, such as labor income risk, housing risk, or financial market risk. In the absence of narrow framing, they must therefore evaluate the $110 / 100$ gamble by mixing it with these other risks and then checking if the combination is attractive. It turns out that the combination is almost always attractive: since the 110/100 gamble is independent of other risks, it offers useful diversification benefits, which, even if loss averse, people can enjoy. The rejection of the 110/100 gamble therefore suggests that people are not fully merging the gamble with their other risks, but that, to some extent, they are evaluating it in isolation; in other words, that they are framing it narrowly.

By the same token, any evidence of aversion to a small, independent, actuarially favorable risk points to a possible role for narrow framing. Examples of such evidence in the field are the high premia consumers pay for telephone wiring insurance and the low deductibles chosen in automobile insurance contracts (Cicchetti and Dubin, 1994, Rabin and Thaler, 2001, Cohen and Einav, 2005). ${ }^{4}$

Motivated by these ideas, some recent papers propose that people are loss averse over changes in the value of their stock market holdings. In other words, even if stock market risk is just one of many risks that determine their overall wealth risk - others being labor income risk and housing risk, say - people still get utility directly from stock market fluctuations (narrow framing) and are more sensitive to losses than to gains (loss aversion).

Is it plausible that people might frame stock market risk narrowly? To answer this, it is helpful to first think about the underlying sources of narrow framing. One view is that narrow framing stems from non-consumption utility, such as regret. Regret is the pain we feel when we realize that we would be better off today if we had taken a different action in the past. Even if a gamble that an agent accepts is just one of many risks that he faces, it

\footnotetext{
${ }^{4}$ For more discussion and evidence of narrow framing, see Kahneman and Tversky (1983), Tversky and Kahneman (1986), Redelmeier and Tversky (1992), Kahneman and Lovallo (1993), and Read, Lowenstein, and Rabin (2000).
} 
is still linked to a specific decision, namely the decision to accept the gamble. As a result, it exposes the agent to possible future regret: if the gamble turns out badly, he may regret the decision to accept it. Consideration of non-consumption utility therefore leads quite naturally to preferences that depend directly on the outcomes of specific gambles the agent faces.

A second interpretation of narrow framing is proposed by Kahneman (2003). He argues that it occurs when decisions are made intuitively, rather than through effortful reasoning. Since intuitive thoughts are by nature spontaneous, they are heavily shaped by the features of the situation at hand that come to mind most easily; to use the technical term, by the features that are most "accessible." When an agent is offered a new gamble, the distribution of the gamble, considered separately, is much more accessible than the distribution of his overall wealth once the new gamble has been merged with his other risks. As a result, if the agent thinks about the gamble intuitively, the distribution of the gamble, taken alone, may play a more important role in decision-making than would be predicted by traditional utility functions defined only over wealth or consumption.

In Tversky and Kahneman's (1981) example, the outcome of each one of choices A, B, $\mathrm{C}$, or $\mathrm{D}$ is highly accessible. Much less accessible, though, is the overall outcome once two choices - A\&D, say, or B\&C - are combined: the distributions in (2) and (3) are less "obvious" than the distributions of A, B, C, and D given in the original question. As a result, the outcome of each of decisions I and II may play a bigger role in decision-making than predicted by traditional utility functions. Similar reasoning applies in the case of the 110/100 gamble.

It seems to us that both the "regret" and "accessibility" interpretations of narrow framing could be relevant when investors - even sophisticated investors - think about stock market risk. Allocating some fraction of his wealth to the stock market constitutes a specific action on the part of the agent - one that he may later regret if his stock market gamble turns out poorly. ${ }^{5}$ Alternatively, given our daily exposure, through newspapers, books, and other media, to large amounts of information about the distribution of stock market risk, such information is very accessible. Much less accessible is information about the distribution of future outcomes once stock risk is merged with the other kinds of risk that people face. Judgments about how much to invest in stocks might therefore be made, at least in part, using a narrow frame.

The accessibility interpretation of narrow framing also provides a rationale for why in-

\footnotetext{
${ }^{5}$ Of course, investing in T-Bills may also lead to regret if the stock market goes up in the meantime. Regret is thought to be stronger, however, when it stems from having taken an action - for example, actively moving one's savings from the default option of a riskless bank account to the stock market - than from having not taken an action - for example, leaving one's savings in place at the bank. In short, errors of commission are more painful than errors of omission (Kahneman and Tversky, 1982).
} 
vestors might focus on annual gains and losses in the stock market. Much of the public discussion about the historical performance of different asset classes is couched in terms of annual returns, making the annual return distribution particularly accessible. ${ }^{6}$

While Tversky and Kahneman's (1981) experiment provides conclusive evidence of narrow framing, it is also somewhat extreme, in that, in this example, narrow framing leads subjects to choose a dominated alternative. In general, narrow framing does not necessarily lead to violations of dominance. All the same, Tversky and Kahneman's (1981) example does raise the concern that, when applied to asset pricing, narrow framing might give rise to arbitrage opportunities. To ensure that this does not happen, the analysis in Section 3 focusses on applications to absolute pricing - in other words, to the pricing of assets, like the aggregate stock market, which lack perfect substitutes. Since the substitutes are imperfect, there are no riskless arbitrage opportunities in the economies we construct. We would not expect narrow framing to have much useful application to relative pricing: in this case, any impact that narrow framing had on prices would create an arbitrage opportunity that could be quickly exploited.

While the regret and accessibility interpretations both suggest that narrow framing may play a role when people evaluate stock market risk, they make different predictions as to how long-lasting this role will be. Under the regret interpretation, the agent simply gets utility from things other than consumption, and takes this into account when making decisions. Since he is acting optimally, there is no reason to expect his behavior to change over time. Narrow framing is therefore likely to be a permanent feature of preferences, and if it leads the agent to demand a high equity premium today, then it will lead him to demand a high equity premium in the future as well.

Suppose, however, that narrow framing instead stems from intuitive thinking and from basing decisions only on "accessible" information. In this case, the agent would be happier with a different decision rule, but has failed to go through the effortful reasoning required to uncover that rule. We would therefore expect the agent's behavior to change over time, as he learns that his intuitive thinking is leading him astray, and either through his own efforts, or by observing the actions of others, discovers a better decision rule. If accessibility-based

\footnotetext{
${ }^{6}$ Clever tests of this logic can be found in Gneezy and Potters (1997) and Thaler et al. (1997). The latter paper, for example, asks subjects how they would allocate between a risk-free asset and a risky asset over a long time horizon such as 30 years. The key manipulation is that some subjects are shown draws from the distribution of asset returns over short horizons - the distribution of monthly returns, say - while others are shown draws from a long-term return distribution - the distribution of 30-year returns, say. Since they have the same decision problem, the two groups of subjects should make similar allocation decisions: subjects who see short-term returns should simply use them to infer the more directly relevant long-term returns. In fact, these subjects allocate substantially less to the risky asset, suggesting that they are simply falling back on the returns that are most accessible to them, namely the short-term returns they were shown. Since losses occur more often in high frequency data, they perceive the risky asset to be especially risky and allocate less to it.
} 
narrow framing is driving the equity premium, we would expect the premium to fall over time as investors gradually switch away from narrow framing.

Our discussion has treated loss aversion and narrow framing as two distinct phenomena. Recent work, however, suggests that they may form a natural pair, because in those situations where people exhibit loss aversion, they often also exhibit narrow framing. For example, as noted above, the rejection of the 110/100 gamble in (1) points not only to loss aversion, but to narrow framing as well.

Kahneman (2003) suggests an explanation for why loss aversion and narrow framing might appear in combination like this. He argues that prospect theory captures the way people act when making decisions intuitively, rather than through effortful reasoning. Since narrow framing is also thought to derive, at least in part, from intuitive decision-making, it is natural that prospect theory, and therefore also loss aversion, would be used in parallel with narrow framing.

\section{The Equity Premium}

In this section, we discuss various ways of modeling loss aversion and narrow framing, and then demonstrate the advantages, from the perspective of addressing the equity premium puzzle, of a model which incorporates these features of decision-making. Specifically, in Section 3.2, we show that such a model can generate a high equity premium at the same time as a low and stable risk-free rate, even when consumption growth is smooth and only weakly correlated with stock returns; and then, in Section 3.3, that it can do so for preference parameters that correspond to reasonable attitudes to large-scale monetary gambles.

\subsection{Modeling loss aversion and narrow framing}

Benartzi and Thaler (1995) are the first to apply loss aversion and narrow framing in the context of the aggregate stock market. They consider an investor who is loss averse over changes in the value of his financial wealth, defined here as holdings of T-Bills and stocks. Since financial wealth is just one component of overall wealth - others being human capital and housing wealth - defining utility directly over fluctuations in financial wealth constitutes narrow framing.

Benartzi and Thaler (1995) argue that, in equilibrium, their investor charges a high equity premium. The reason is that the high volatility of stock returns leads to substantial volatility in returns on financial wealth. Given that he is more sensitive to losses than to gains, these fluctuations in his financial wealth cause the investor substantial discomfort. As 
a result, he only holds the market supply of stocks if compensated by a high average return.

A weakness of Benartzi and Thaler's (1995) framework is that, since the investor gets direct utility only from changes in the value of his financial wealth, and none at all from consumption or total wealth, consumption plays no role, making it hard to check how well the model describes the joint properties of stock returns and consumption growth. An important challenge therefore remains: to build and evaluate a more realistic model in which, even if the investor gets utility from fluctuations in the value of one component of his wealth, he also gets some utility from consumption.

Barberis, Huang, and Santos (2001) take up this challenge. Before presenting their specification, we introduce the basic economic structure that will apply throughout our essay. At time $t$, the investor, whose wealth is denoted $W_{t}$, chooses a consumption level $C_{t}$ and allocates his post-consumption wealth, $W_{t}-C_{t}$, across three assets. The first asset is risk-free, and earns a gross return of $R_{f, t}$ between $t$ and $t+1$. The second asset is the stock market, which earns a gross return of $R_{S, t+1}$ over the same interval, and the third is a non-financial asset, such as human capital or housing wealth, which earns a gross return of $R_{N, t+1}$. The investor's wealth therefore evolves according to

$$
W_{t+1}=\left(W_{t}-C_{t}\right)\left(\left(1-\theta_{S, t}-\theta_{N, t}\right) R_{f, t}+\theta_{S, t} R_{S, t+1}+\theta_{N, t} R_{N, t+1}\right) \equiv\left(W_{t}-C_{t}\right) R_{W, t+1},
$$

where $\theta_{S, t}\left(\theta_{N, t}\right)$ is the fraction of post-consumption wealth allocated to the stock market (the non-financial asset) and $R_{W, t+1}$ is the gross return on wealth between $t$ and $t+1$.

A stripped-down version of Barberis, Huang, and Santos' (2001) framework can be written as follows. The investor maximizes

$$
E_{0} \sum_{t=0}^{\infty}\left[\beta^{t} \frac{C_{t}^{1-\gamma}}{1-\gamma}+b_{0} \beta^{t+1} \bar{C}_{t}^{-\gamma} \bar{v}\left(G_{S, t+1}\right)\right],
$$

subject to the standard budget constraint, where

$$
\begin{aligned}
G_{S, t+1} & =\theta_{S, t}\left(W_{t}-C_{t}\right)\left(R_{S, t+1}-1\right) \\
\bar{v}(x) & =\left\{\begin{array}{l}
x \\
\lambda x
\end{array} \text { for } \begin{array}{l}
x \geq 0 \\
x<0
\end{array}, \lambda>1,\right.
\end{aligned}
$$

and where $\bar{C}_{t}$ is aggregate per-capita consumption.

The first term inside the parenthesis in (5) ensures that, as in traditional models, the investor gets utility directly from consumption. Consumption utility takes the standard, time-additive, power form analyzed by Mehra and Prescott (1985). The parameter $\beta$ is the time discount factor, while $\gamma>0$ controls the curvature of the utility function.

The second term introduces narrow framing and loss aversion. The variable $G_{S, t+1}$ is the change in the value of the investor's stock market holdings, computed as stock market 
wealth at time $t, \theta_{S, t}\left(W_{t}-C_{t}\right)$, multiplied by the net stock market return, $R_{S, t+1}-1 ; \bar{v}\left(G_{S, t+1}\right)$ represents utility from this change in value. Narrow framing is therefore introduced by letting the agent get utility directly from changes in the value of just one component of his total wealth, with $b_{0}$ controlling the degree of narrow framing. Loss aversion is introduced via the piecewise linear form of $\bar{v}(\cdot)$, which makes the investor more sensitive to declines in stock market value than to increases. Finally, $\bar{C}_{t}^{-\gamma}$ is a neutral scaling term that ensures stationarity in equilibrium.

Equation (6) is the simplest way of specifying the stock market "gains" and "losses" that the investor is loss averse over. Here, so long as $\theta_{S, t}>0$, a positive net return is considered a gain and, from (7), is assigned positive utility; a negative net return is considered a loss and is assigned negative utility. Barberis, Huang, and Santos (2001) work primarily with another, possibly more realistic formulation,

$$
G_{S, t+1}=\theta_{S, t}\left(W_{t}-C_{t}\right)\left(R_{S, t+1}-R_{f, t}\right)
$$

in which a stock market return is only considered a gain, and hence is only assigned positive utility, if it exceeds the risk-free rate.

In Section 2, we noted that even though narrow framing has mainly been documented in experimental settings, both the "regret" and "accessibility" interpretations suggest that people may frame the stock market narrowly as well. One could argue that they also suggest that people will frame their non-financial assets narrowly: for example, on the grounds that the distribution of those assets' returns is also very accessible. The specification in (5) can certainly accommodate such behavior, but we have found that doing so has little effect on our results. For simplicity, then, we assume that only stock market risk is framed narrowly.

The preferences in (5) are a simplified version of Barberis, Huang, and Santos' (2001) specification. In an effort to understand not only the equity premium, but also the volatility and time-series predictability of stock returns, their original model captures not only loss aversion, but also some dynamic evidence on loss aversion, sometimes known as the "house money" effect, whereby prior gains and losses affect current sensitivity to losses. The specification in (5) strips out this dynamic effect, leaving only the core features of loss aversion and narrow framing. We discuss the full model in Section $5 .^{7}$

The first-order conditions of optimality for the preferences in (5), (7), and (8) can be derived using straightforward perturbation arguments. They are:

$$
1=\beta R_{f, t} E_{t}\left[\left(\frac{\bar{C}_{t+1}}{\bar{C}_{t}}\right)^{-\gamma}\right]
$$

\footnotetext{
${ }^{7}$ Barberis, Huang, and Santos (2001) also consider the case in which the investor gets utility from changes in total wealth, rather than in stock market wealth, so that there is no narrow framing.
} 


$$
1=\beta E_{t}\left[R_{S, t+1}\left(\frac{\bar{C}_{t+1}}{\bar{C}_{t}}\right)^{-\gamma}\right]+b_{0} \beta E_{t}\left(\bar{v}\left(R_{S, t+1}-R_{f, t}\right)\right) .
$$

When there is no narrow framing, so that $b_{0}=0$, these equations reduce to those derived from a standard asset pricing model with time-additive power utility over consumption, such as that of Mehra and Prescott (1985). Introducing narrow framing, so that $b_{0}>0$, has no effect on the first-order condition for the risk-free rate, condition (9): consuming a little less today and investing the savings in the risk-free rate does not change the investor's exposure to losses in the stock market. Narrow framing does, however, introduce a second term in the first-order condition for the stock market, condition (10): consuming less today and investing the proceeds in the stock market exposes the investor to potentially greater disutility from a drop in the stock market.

Barberis, Huang, and Santos (2001) assign the preferences in (5), (7), and (8) to the representative agent in a simple endowment economy, and, using conditions (9)-(10), show that, when the model is calibrated to annual data, the narrow framing term can generate a substantial equity premium and a low and stable risk-free rate, even when consumption growth is smooth and only weakly correlated with stock returns. Much as in Benartzi and Thaler (1995), the intuition is that, since the investor gets direct utility from changes in the value of his stock market holdings, and is more sensitive to losses than to gains, he perceives the stock market to be very risky and only holds the market supply if compensated by a high average return.

Of course, in assigning the utility function in (5) to a representative agent, Barberis, Huang, and Santos (2001) are assuming that the key features of these preferences survive aggregation. Intuitively, if all investors are loss averse over annual fluctuations in stock market wealth, it is hard to see why this would "wash out" in the aggregate. However, this point has not yet been formalized.

While the preference specification in (5) yields a number of insights, it also has some limitations. First, it does not admit an explicit value function. This makes it hard to compute attitudes to independent monetary gambles, and therefore to check whether the preference parameters $\left(\gamma, \lambda, b_{0}\right)$ used to generate a high equity premium are reasonable or not. Second, the preferences in (5) are intractable in partial equilibrium settings, and so cannot be used to investigate the implications of narrow framing for portfolio choice. Finally, to ensure stationarity, the narrow framing component has to be scaled by an ad-hoc factor based on aggregate consumption.

Recently, Barberis and Huang (2004) have proposed a new preference specification that overcomes these limitations. Their starting point is a non-expected utility formulation known as recursive utility, in which the agent's time $t$ utility, $V_{t}$, is given by

$$
V_{t}=W\left(C_{t}, \mu\left(V_{t+1} \mid I_{t}\right)\right),
$$


where $\mu\left(V_{t+1} \mid I_{t}\right)$ is the certainty equivalent of the distribution of future utility, $V_{t+1}$, conditional on time $t$ information $I_{t}$, and $W(\cdot, \cdot)$ is an aggregator function that aggregates current consumption $C_{t}$ with the certainty equivalent of future utility to give current utility (see Epstein and Zin, 1989, for a detailed discussion). Most implementations of recursive utility assign $W(\cdot, \cdot)$ the form

$$
W(C, y)=\left((1-\beta) C^{\rho}+\beta y^{\rho}\right)^{\frac{1}{\rho}}, 0<\beta<1,0 \neq \rho<1,
$$

where $\beta$ is a time discount factor and $\rho$ controls the elasticity of intertemporal substitution. Most implementations also assume homogeneity of $\mu(\cdot)$. If a certainty equivalent functional is homogeneous, it is necessarily homogeneous of degree one, so that

$$
\mu(k z)=k \mu(z), k>0
$$

In its current form, the specification in equation (11) does not allow for narrow framing: an investor with these preferences only cares about the outcome of a gamble he is offered to the extent that that outcome affects his overall wealth risk. Barberis and Huang (2004) show, however, that these preferences can be extended to accommodate narrow framing. They specify their utility function in a general context, but for the specific three-asset setting introduced earlier, their formulation reduces to

$$
V_{t}=W\left(C_{t}, \mu\left(V_{t+1} \mid I_{t}\right)+b_{0} E_{t}\left(\bar{v}\left(G_{S, t+1}\right)\right)\right),
$$

where

$$
\begin{aligned}
W(C, y) & =\left((1-\beta) C^{\rho}+\beta y^{\rho}\right)^{\frac{1}{\rho}}, 0<\beta<1,0 \neq \rho<1 \\
\mu(k z) & =k \mu(z), k>0 \\
G_{S, t+1} & =\theta_{S, t}\left(W_{t}-C_{t}\right)\left(R_{S, t+1}-R_{f, t}\right) \\
\bar{v}(x) & =\left\{\begin{array}{ll}
x & \text { for } \begin{array}{l}
x \geq 0 \\
\lambda x
\end{array}
\end{array}, \lambda>1 .\right.
\end{aligned}
$$

Relative to the usual recursive specification in equation (11), this new formulation maintains the standard assumptions for $W(\cdot, \cdot)$ and $\mu(\cdot)$. The difference is that a new term, that captures loss aversion and narrow framing, has been added to the second argument of $W(\cdot, \cdot)$. As before, $G_{S, t+1}$ represents changes in the value of the investor's stock market holdings, measured relative to the risk-free rate. By letting the investor get direct utility $\bar{v}\left(G_{S, t+1}\right)$ from changes in the value of this one component of his wealth, we are introducing narrow framing, with the degree of narrow framing again controlled by $b_{0}$. Loss aversion is introduced through the piecewise linearity of $\bar{v}(\cdot)$, just as in the earlier specification in (5). ${ }^{8}$

\footnotetext{
${ }^{8}$ It is straightforward to also allow for the narrow framing of the non-financial asset. Doing so does not have a significant effect on our results.
} 
Since our focus is on the effects of narrow framing, we give the certainty equivalent functional $\mu(\cdot)$ the simplest possible form, namely

$$
\mu(z)=\left(E\left(z^{\zeta}\right)\right)^{\frac{1}{\zeta}},
$$

where the exponent $\zeta$ is set to the same value as the exponent in the aggregator function, $\rho$. We denote this common value $1-\gamma$, so that

$$
\rho=\zeta=1-\gamma .
$$

\subsection{Quantitative implications}

We now use the specification in equation (14) to illustrate two benefits of the narrow framing approach in more detail: first, that it can generate a high equity premium at the same time as a low and stable risk-free rate, even when consumption growth is smooth and only weakly correlated with stock returns; and then in Section 3.3, that it can do so while also making sensible predictions about attitudes to large-scale monetary gambles.

To see the first result, consider a simple economy with a representative agent who has the preferences in equation (14). As before, there are three assets: a risk-free asset in zero

net supply, and two risky assets, a stock market and a non-financial asset, both in positive net supply. Barberis and Huang (2004) show that, in this setting, the first-order conditions of optimality are

$$
\begin{aligned}
1 & =\left[\beta R_{f, t} E_{t}\left(\left(\frac{C_{t+1}}{C_{t}}\right)^{-\gamma}\right)\right]\left[\beta E_{t}\left(\left(\frac{C_{t+1}}{C_{t}}\right)^{-\gamma} R_{W, t+1}\right)\right]^{\frac{\gamma}{1-\gamma}} \\
0 & =\frac{E_{t}\left(\left(\frac{C_{t+1}}{C_{t}}\right)^{-\gamma}\left(R_{S, t+1}-R_{f, t}\right)\right)}{E_{t}\left(\left(\frac{C_{t+1}}{C_{t}}\right)^{-\gamma}\right)}+b_{0} R_{f, t}\left(\frac{\beta}{1-\beta}\right)^{\frac{1}{1-\gamma}}\left(\frac{1-\alpha_{t}}{\alpha_{t}}\right)^{\frac{-\gamma}{1-\gamma}} E_{t}\left(\bar{v}\left(R_{S, t+1}-R_{f, t}\right)\right) \\
0 & =\frac{E_{t}\left(\left(\frac{C_{t+1}}{C_{t}}\right)^{-\gamma}\left(R_{W, t+1}-R_{f, t}\right)\right)}{E_{t}\left(\left(\frac{C_{t+1}}{C_{t}}\right)^{-\gamma}\right)}+b_{0} R_{f, t}\left(\frac{\beta}{1-\beta}\right)^{\frac{1}{1-\gamma}}\left(\frac{1-\alpha_{t}}{\alpha_{t}}\right)^{\frac{-\gamma}{1-\gamma}} \theta_{S, t} E_{t}\left(\bar{v}\left(R_{S, t+1}-R_{f,(D)}(2)\right)\right.
\end{aligned}
$$

where $\alpha_{t} \equiv C_{t} / W_{t}$ is the consumption-wealth ratio, and where $R_{W, t+1}$ is defined in equation (4).

We consider an equilibrium in which: (i) the risk-free rate is a constant $R_{f}$; (ii) consumption growth and stock returns are distributed as

$$
\begin{aligned}
\log \frac{C_{t+1}}{C_{t}} & =g_{C}+\sigma_{C} \varepsilon_{C, t+1} \\
\log R_{S, t+1} & =g_{S}+\sigma_{S} \varepsilon_{S, t+1},
\end{aligned}
$$

where

$$
\left(\begin{array}{c}
\varepsilon_{C, t} \\
\varepsilon_{S, t}
\end{array}\right) \sim N\left(\left(\begin{array}{l}
0 \\
0
\end{array}\right),\left(\begin{array}{ll}
1 & \rho_{C S} \\
\rho_{C S} & 1
\end{array}\right)\right) \text {, i.i.d. over time; }
$$


(iii) the consumption-wealth ratio $\alpha_{t}$ is a constant $\alpha$, which, using

$$
R_{W, t+1}=\frac{W_{t+1}}{W_{t}-C_{t}}=\frac{1}{1-\alpha} \frac{C_{t+1}}{C_{t}}
$$

implies that

$$
\log R_{W, t+1}=g_{W}+\sigma_{W} \varepsilon_{W, t+1}
$$

where

$$
\begin{aligned}
g_{W} & =g_{C}+\log \frac{1}{1-\alpha} \\
\sigma_{W} & =\sigma_{C} \\
\varepsilon_{W, t+1} & =\varepsilon_{C, t+1}
\end{aligned}
$$

and (iv) the fraction of total wealth made up by the stock market, $\theta_{S, t}$, is a constant over time, $\theta_{S}$, so that

$$
\theta_{S, t}=\frac{S_{t}}{S_{t}+N_{t}}=\theta_{S}, \forall t
$$

where $S_{t}$ and $N_{t}$ are the total market value of the stock and of the non-financial asset, respectively. Barberis and Huang (2004) demonstrate that this structure, while restrictive, can be embedded in a general equilibrium framework with endogeneous production.

Barberis and Huang (2004) also show that, under this structure, equations (21)-(23) simplify to

$$
\begin{aligned}
\alpha= & 1-\beta^{\frac{1}{\gamma}} R_{f}^{\frac{1-\gamma}{\gamma}} e^{\frac{1}{2}(1-\gamma) \sigma_{C}^{2}} \\
0= & b_{0} R_{f}\left(\frac{\beta}{1-\beta}\right)^{\frac{1}{1-\gamma}}\left(\frac{1-\alpha}{\alpha}\right)^{\frac{-\gamma}{1-\gamma}}\left[e^{g_{S}+\frac{1}{2} \sigma_{S}^{2}}-R_{f}+(\lambda-1)\left[e^{g_{S}+\frac{1}{2} \sigma_{S}^{2}} N\left(\widehat{\varepsilon}_{S}-\sigma_{S}\right)-R_{f} N\left(\widehat{\varepsilon}_{S}\right)\right]\right]+ \\
& e^{g_{S}+\frac{1}{2} \sigma_{S}^{2}-\gamma \sigma_{S} \sigma_{C} \rho_{C S}}-R_{f} \\
0= & b_{0} R_{f}\left(\frac{\beta}{1-\beta}\right)^{\frac{1}{1-\gamma}}\left(\frac{1-\alpha}{\alpha}\right)^{\frac{-\gamma}{1-\gamma}} \theta_{S}\left[e^{g_{S}+\frac{1}{2} \sigma_{S}^{2}}-R_{f}+(\lambda-1)\left[e^{g_{S}+\frac{1}{2} \sigma_{S}^{2}} N\left(\widehat{\varepsilon}_{S}-\sigma_{S}\right)-R_{f} N\left(\widehat{\varepsilon}_{S}\right)\right]\right]+ \\
& \frac{1}{1-\alpha} e^{g_{C}+\frac{1}{2} \sigma_{C}^{2}-\gamma \sigma_{C}^{2}}-R_{f},
\end{aligned}
$$

where

$$
\widehat{\varepsilon}_{S}=\frac{\log R_{f}-g_{S}}{\sigma_{S}}
$$

We use equations (33)-(35) to compute the equilibrium equity premium. First, we set the return and consumption process parameters to the values in Table 1 . These values are estimated from annual data spanning the 20th century and are standard in the literature. Then, for given preference parameters $\beta, \gamma, b_{0}$, and $\lambda$, and for a given stock market fraction of total wealth $\theta_{S}$, equations (33)-(35) can be solved for $\alpha, R_{f}$, and $g_{S}$, thereby giving us the equity premium. 
Table 2 presents the results. We take $\beta=0.98$ and $\theta_{S}=0.2$, and consider various values of $\gamma, \lambda$, and $b_{0}$. The parameter $\beta$ has little effect on attitudes to risk; setting it to 0.98 ensures that the risk-free rate is not too high. Our results are quantitatively similar for a range of values of $\theta_{S}$.

The table confirms that narrow framing of stocks can generate a substantial equity premium at the same time as a low risk-free rate, even when, as shown in Table 1, consumption growth is smooth and only weakly correlated with stock returns. For example, the parameter values $\left(\gamma, \lambda, b_{0}\right)=(1.5,2,0.1)$ produce an equity premium of $4.63 \%$ and a risk-free rate of $3.4 \%$, while $\left(\gamma, \lambda, b_{0}\right)=(1.5,3,0.1)$ produce a premium as high as $8.12 \%$ with a risk-free rate of only $2.3 \%$. The intuition is the same as in Benartzi and Thaler (1995) and Barberis, Huang, and Santos (2001): if the agent gets utility directly from changes in the value of the stock market and, via the parameter $\lambda$, is more sensitive to losses than to gains, he perceives the stock market to be very risky and only holds the available supply if compensated by a high average return.

The assumption that the agent evaluates stock market gains and losses on an annual basis is important for our results, but not critical. Table 3 reports equity premia for an investor with the preferences in equation (14), but who evaluates stock market gains and losses at intervals other than a year. The table shows that, even though the equity premium declines as the interval grows, long evaluation periods can still generate substantial equity premia at the same time as a low risk-free rate.

The intuition for why the equity premium is lower for longer evaluation periods, first pointed out by Benartzi and Thaler (1995), is straightforward. Since the distribution of stock returns has a positive mean, the probability of seeing a drop in the stock market falls as returns are aggregated at longer intervals. While annual stock returns might be negative $40 \%$ of the time, five-year returns are negative less often. A loss averse agent is therefore less scared of stocks when he evaluates their returns at longer intervals, and, as a result, demands a lower equity premium.

\subsection{Attitudes to large monetary gambles}

We now demonstrate another attractive feature of the preference specification in equation (14), namely that it can deliver a high equity premium for parameterizations that are "reasonable," in the sense that they correspond to sensible attitudes to independent monetary gambles. This is important because it was, in part, the difficulty researchers encountered in reconciling the equity premium with attitudes to monetary gambles that launched the equity premium literature in the first place. Economists are primarily interested in attitudes to large-scale monetary gambles, so we begin with those. In Section 3.4, we also consider 
attitudes to small-scale gambles.

The literature has suggested a number of thought experiments involving large-scale gambles. Epstein and Zin (1990) and Kandel and Stambaugh (1991) consider an individual with wealth of $\$ 75,000$ and ask what premium he would pay to avoid a 50:50 chance of losing $\$ 25,000$ or gaining the same amount; in Kandel and Stambaugh's (1991) view, a premium of $\$ 24,000$ is too high, but a premium of $\$ 8,333$ is more reasonable. Mankiw and Zeldes (1991) think about the value of $x$ for which an agent would be indifferent between certain consumption of $\$ x$ and a 50:50 chance of $\$ 50,000$ consumption or $\$ 100,000$ consumption. Rabin (2000) suggests a mild condition, namely that an agent should accept a clearly attractive large gamble such as a 50:50 bet to win $\$ 20$ million against a $\$ 10,000$ loss.

It does not matter, for our results, which of these thought experiments we use. In what follows, we focus on the one suggested by Epstein and Zin (1990) and Kandel and Stambaugh (1991). In our view, a reasonable condition to impose is: ${ }^{9}$

Condition L: An individual with wealth of $\$ 75,000$ should not pay a premium higher than $\$ 15,000$ to avoid a 50:50 chance of losing $\$ 25,000$ or gaining the same amount.

Barberis and Huang (2004) show that, to avoid a gamble $g$ offering an equal chance to win or lose $x$, an investor with the preferences in equation (14) would pay a premium equal to

$$
\pi=\frac{A\left(W_{t}-\left(E\left(W_{t}+g\right)^{1-\gamma}\right)^{\frac{1}{1-\gamma}}\right)+b_{0} \frac{x}{2}(\lambda-1)}{A+b_{0} \lambda}
$$

where

$$
A=(1-\beta)^{\frac{1}{1-\gamma}} \alpha^{-\frac{\gamma}{1-\gamma}},
$$

with $\alpha$ already computed in equations (33)-(35) above. In this calculation, they make the simplest possible assumption, namely that, whatever degree of narrow framing $b_{0}$ and level of loss aversion $\lambda$ the investor uses when thinking about stock market risk, he also uses when thinking about the independent monetary gamble $g$. When $b_{0}=0$, equation (37) gives the premium that would be charged by an agent with standard power utility preferences. When $b_{0}>0$, the premium in equation (37) reflects the fact that, to some extent, the investor is framing gamble $g$ narrowly. For large $b_{0}$, equation (37) reduces to

$$
\pi=\frac{x}{2 \lambda}(\lambda-1)
$$

the premium that would be charged by an agent who evaluates gamble $g$ completely in isolation and who is $\lambda$ times as sensitive to losses as to gains.

Using equation (37), the right-most columns in Tables 2 and 3 show, for each parameterization, the amount that the representative agent would pay, given his equilibrium holdings of

\footnotetext{
${ }^{9}$ We use the label "condition L" to emphasize that we are thinking about Large-scale gambles.
} 
risky assets, to avoid the symmetric bet in condition L. The rows in which $b_{0}=0$ reproduce a well-known result: that for power utility preferences, those values of $\gamma$ low enough to make sensible predictions about attitudes to large-scale monetary gambles inevitably generate too low an equity premium.

Table 2 shows, however, that as soon as narrow framing is allowed - in other words, as soon as $b_{0}>0$ - it is easy to find parameterizations that give a high equity premium while also satisfying condition L. When $\left(\gamma, \lambda, b_{0}\right)=(1.5,2,0.1)$, for example, the investor charges a substantial equity premium of $4.63 \%$, and a reasonable $\$ 6,269$ to avoid the $\pm \$ 25,000$ gamble.

How is it that the preference specification in equation (14) can reconcile attitudes to stock market risk and to the large-scale monetary gamble in condition $\mathrm{L}$ when other specifications have trouble doing so? To see how, note first that, in the simple representative agent economy described by conditions (i)-(iv) in Section 3.2, the equity premium is determined by the agent's attitude, in equilibrium, to adding a small amount of stock market risk to a portfolio that is only weakly correlated with the stock market. Why can we say "weakly" correlated? Since representative agent economies are calibrated to aggregate data, the correlation of stock returns and consumption growth, $\rho_{C S}$, must be set to a low value; given that the consumption-wealth ratio is constant, this immediately implies a low correlation between stock returns and returns on total wealth. ${ }^{10}$

To generate a substantial equity premium, then, we need the agent to be strongly averse or, at the very least, moderately averse, to a small, weakly correlated gamble. To satisfy condition L, we need the agent to be mildly averse or, at most, moderately averse, to a large, independent gamble.

Now consider the two functions in the second argument of $W(\cdot, \cdot)$ in equation (14), namely $\mu(\cdot)$ and $\bar{v}(\cdot)$. For a $\gamma$ of 1.5 , the $\mu(\cdot)$ term, by virtue of its local risk-neutrality, produces only mild aversion to a small, weakly correlated gamble, but moderate aversion to a large, independent gamble. For a $\lambda$ of 2 , the $\bar{v}(\cdot)$ term, by virtue of being piecewise linear, produces moderate aversion both to a small, weakly correlated gamble and to a large, independent gamble. For a degree of narrow framing $b_{0}$ that is high enough, the two terms therefore generate moderate aversion to a small, weakly correlated gamble - thereby giving a substantial equity premium - and moderate aversion to a large, independent gamble, thereby satisfying condition L.

\footnotetext{
${ }^{10}$ Of course, in more general representative agent economies, the consumption-wealth ratio need not be constant. So long as the ratio is sufficiently stable, however, it should still follow that stock returns and returns on total wealth are only weakly correlated.
} 


\subsection{Attitudes to small monetary gambles}

In Section 3.3, we saw that the preferences in equation (14), capturing both loss aversion and narrow framing, can generate a large equity premium for preference parameters that also correspond to sensible attitudes to large-scale monetary gambles, in that they satisfy condition L. In fact, condition L does not put very sharp restrictions on the range of equity premia that we can generate: as Table 2 shows, it can be consistent with premia as low as $0.12 \%$ or as high as $8.12 \%$.

In this section, we show that by requiring the preference specification in equation (14) to also make sensible predictions about attitudes to small-scale gambles, we can put tighter bounds on the range of equity premia that narrow framing can plausibly generate. The intuition is straightforward. As argued earlier, in the simple representative agent economy of Section 3.2, the equity premium is determined by the agent's attitude, in equilibrium, to adding a small amount of weakly correlated stock market risk to the rest of his portfolio. If we impose constraints on the investor's attitude to a small, independent risk, it is likely that we will also constrain his attitude to a small, weakly correlated risk and thereby also, the equity premium he will charge.

What condition should we impose on attitudes to small-scale gambles? As with largescale gambles, the earlier literature has suggested a number of relevant thought experiments. For consistency with our earlier discussion, we return to Epstein and Zin (1990), who ask how much an individual with wealth of $\$ 75,000$ would pay to avoid a 50:50 bet to lose $\$ 250$ or to win the same amount. In our view, a reasonable condition to impose here is: ${ }^{11}$

Condition S: An individual with wealth of $\$ 75,000$ should not pay a premium higher than $\$ 40$ to avoid a 50:50 chance of losing $\$ 250$ or gaining the same amount.

Figure 1 shows how condition $\mathrm{S}$ sharply restricts the range of equity premia that can be generated by the preferences in equation (14). The " $\mathrm{x}$ " signs show, for $\gamma=1.5$, the values of $\lambda$ and $b_{0}$ that produce equity premia higher than $5 \%$. Clearly, either a high sensitivity to losses $\lambda$, or a high degree of narrow framing $b_{0}$, or both, are required to generate equity premia as large as $5 \%$. Note that our earlier condition on attitudes to large-scale gambles, condition $\mathrm{L}$, is satisfied by all values of $\lambda$ and $b_{0}$ spanned by the graph - in other words, by all pairs $\left(\lambda, b_{0}\right) \epsilon[0,4] \times[0,0.1]$. If condition $\mathrm{L}$ were the only condition constraining our choice of preference parameters, we could therefore easily obtain premia higher than $5 \%$.

The "+" signs in the figure show the values of $\lambda$ and $b_{0}$ that satisfy condition S. Imposing this condition severely restricts the range of feasible values of $\lambda$ and $b_{0}$. In fact, we cannot obtain an equity premium as high as $5 \%$ without violating it.

\footnotetext{
${ }^{11}$ We use the label "condition S" to emphasize that we are thinking about Small-scale gambles.
} 
Even though condition $\mathrm{S}$ does restrict the feasible parameter set, it still allows for sizeable equity premia. Table 4 lists some parameter values that satisfy both condition $\mathrm{L}$ and condition $\mathrm{S}$, and yet still produce equity premia above $3 \%$.

\subsection{The importance of narrow framing}

While narrow framing is admittedly an unusual feature of preferences, it is crucial to our results. To demonstrate this, we now show that, in the absence of narrow framing, it becomes much harder to replicate some of the attractive features of the preferences in equation (14) - much harder, for example, to reconcile a high equity premium with reasonable attitudes to large-scale monetary gambles, and, in particular, with the attitudes imposed by condition L.

Consider a model in which the agent is loss averse over annual changes in total wealth, rather than in stock market wealth. Such a model maintains the assumptions of loss aversion and of annual evaluation of gains and losses, but by changing the focus from gains and losses in stock market wealth to gains and losses in total wealth, it removes the narrow framing. One such preference specification is the following:

$$
V_{t}=W\left(C_{t}, \mu\left(V_{t+1} \mid I_{t}\right)\right)
$$

where

$$
W(C, y)=\left((1-\beta) C^{\rho}+\beta y^{\rho}\right)^{\frac{1}{\rho}}, 0<\beta<1,0 \neq \rho<1,
$$

and where the certainty equivalent functional $\mu(\cdot)$ takes a form proposed by Gul (1991), often referred to as "disappointment aversion":

$$
\mu(V)^{1-\gamma}=E\left(V^{1-\gamma}\right)+(\lambda-1) E\left(\left(V^{1-\gamma}-\mu(V)^{1-\gamma}\right) 1(V<\mu(V))\right), 0<\gamma \neq 1, \lambda>1 .
$$

While the specification in (42) looks somewhat messy, it is simply a function with a kink, which makes the investor more sensitive to losses than to gains. The parameter $\lambda$ controls the relative sensitivity to losses. ${ }^{12}$

We consider a simple economy with a representative agent who has the preferences in equations (40)-(42). The market structure is the same as before. There are three risky assets: a risk-free asset, in zero net supply, and two risky assets, a stock market and a non-financial asset, each in positive net supply. Epstein and Zin (1989) show that the first-order conditions of optimality are:

$$
0=E_{t}\left[\phi\left(\beta^{\frac{1}{\rho}}\left(\frac{C_{t+1}}{C_{t}}\right)^{\frac{\rho-1}{\rho}} R_{W, t+1}^{\frac{1}{\rho}}\right)\right]
$$

\footnotetext{
${ }^{12}$ Epstein and Zin (2001) and Ang, Bekaert, and Liu (2005) discuss the implementation of disappointment aversion in dynamic environments.
} 


$$
\begin{aligned}
& 0=E_{t}\left[\phi^{\prime}\left(\beta^{\frac{1}{\rho}}\left(\frac{C_{t+1}}{C_{t}}\right)^{\frac{\rho-1}{\rho}} R_{W, t+1}^{\frac{1}{\rho}}\right)\left(\frac{C_{t+1}}{R_{W, t+1}}\right)^{\frac{\rho-1}{\rho}}\left(R_{S, t+1}-R_{f, t}\right)\right] \\
& 0=E_{t}\left[\phi^{\prime}\left(\beta^{\frac{1}{\rho}}\left(\frac{C_{t+1}}{C_{t}}\right)^{\frac{\rho-1}{\rho}} R_{W, t+1}^{\frac{1}{\rho}}\right)\left(\frac{C_{t+1}}{R_{W, t+1}}\right)^{\frac{\rho-1}{\rho}}\left(R_{W, t+1}-R_{f, t}\right)\right],
\end{aligned}
$$

where

$$
\phi(x)=\left\{\begin{array}{l}
\frac{x^{1-\gamma}-1}{1-\gamma} \\
\lambda \frac{x^{1-\gamma}-1}{1-\gamma}
\end{array} \quad \text { for } \begin{array}{l}
x \geq 1 \\
x<1
\end{array} .\right.
$$

We look for a simple equilibrium in which conditions (i)-(iii) of Section 3.2 hold. ${ }^{13}$ Under these conditions, equations (43)-(45) become

$$
\begin{aligned}
0 & =\left(\frac{\beta}{1-\alpha}\right)^{\frac{1-\gamma}{\rho}} C_{1}-1+(\lambda-1)\left(\frac{\beta}{1-\alpha}\right)^{\frac{1-\gamma}{\rho}} C_{1} N\left(\bar{\varepsilon}_{C}-(1-\gamma) \sigma_{C}\right)-(\lambda-1) N\left(\bar{\varepsilon}_{C}\right) \\
0 & =C_{2}-R_{f} C_{3}+(\lambda-1)\left(C_{2} N\left(\bar{\varepsilon}_{C}-\sigma_{S} \rho_{C S}+\gamma \sigma_{C}\right)-R_{f} C_{3} N\left(\bar{\varepsilon}_{C}+\gamma \sigma_{C}\right)\right) \\
0 & =\frac{1}{1-\alpha} C_{1}-R_{f} C_{3}+(\lambda-1)\left(\frac{C_{1}}{1-\alpha} N\left(\bar{\varepsilon}_{C}-(1-\gamma) \sigma_{C}\right)-R_{f} C_{3} N\left(\bar{\varepsilon}_{C}+\gamma \sigma_{C}\right)\right)
\end{aligned}
$$

where

$$
\begin{aligned}
C_{1} & =\exp \left((1-\gamma) g_{C}+\frac{1}{2}(1-\gamma)^{2} \sigma_{C}^{2}\right) \\
C_{2} & =\exp \left(g_{S}-\gamma g_{C}+\frac{1}{2}\left(\sigma_{S}^{2}-2 \gamma \sigma_{S} \sigma_{C} \rho_{C S}+\gamma^{2} \sigma_{C}^{2}\right)\right) \\
C_{3} & =\exp \left(-\gamma g_{C}+\frac{1}{2} \gamma^{2} \sigma_{C}^{2}\right) \\
\bar{\varepsilon}_{C} & =-\frac{1}{\sigma_{C}}\left(g_{C}+\frac{1}{\rho} \log \left(\frac{\beta}{1-\alpha}\right)\right),
\end{aligned}
$$

and where $N(\cdot)$ is the cumulative Normal distribution function.

We use equations (47)-(49) to compute the equilibrium equity premium. As before, we set the return and consumption process parameters to the values in Table 1 . Then, for given preference parameters $\beta, \rho$, and $\gamma$, we use equation (47) to compute the consumption-wealth ratio $\alpha$, equation (49) to compute the risk-free rate $R_{f}$, and equation (48) to compute the mean log stock return $g_{S}$.

To check whether the parameters corresponding to any particular equity premium are reasonable - in other words, whether they satisfy condition L - we need to know the premium an agent with the preferences in equations (40)-(42) would pay to avoid a gamble to win or lose $x$ with equal chance. Following the analysis in Epstein and Zin (1989), it can be shown that the premium $\pi$ is given by

$$
\frac{\pi}{W_{t}}=1-\left(\frac{\left(1+\frac{x}{W_{t}}\right)^{1-\gamma}+\lambda\left(1-\frac{x}{W_{t}}\right)^{1-\gamma}}{1+\lambda}\right)^{\frac{1}{1-\gamma}} .
$$

\footnotetext{
${ }^{13}$ It is straightforward to show that such a structure can be embedded in a general equilibrium model.
} 
The parameters $\beta$ and $\rho$ have little effect on attitudes to risk. We set them to 0.95 and -1 , respectively, to ensure that the risk-free rate is not too high. The area shaded with "+" signs in Figure 2 shows the values of $\gamma$ and $\lambda$ for which the representative agent satisfies condition L; in other words, the values for which, given his equilibrium holdings of risky assets and wealth of $\$ 75,000$, he pays a premium below $\$ 15,000$ to avoid a 50:50 chance of losing $\$ 25,000$ or winning the same amount. The area shaded with " $\mathrm{x}$ " signs shows the values of $\gamma$ and $\lambda$ for which the representative agent charges an equity premium higher than $2 \%$. There is no overlap between the two regions: in fact, the largest equity premium that we can generate with this preference specification under condition $\mathrm{L}$ is $0.93 \%$, far smaller than the equity premia derived from narrow framing in Table $2 .{ }^{14}$

To see the intuition for this result, recall from Section 3.3 that, in the simple, representative agent economy considered here, the equity premium is determined by the agent's attitude, in equilibrium, to adding an extra dollar of stock market risk to a portfolio that is only weakly correlated with the stock market. In the absence of narrow framing, the agent evaluates this extra risk by merging it with his other risks and checking if the combination is attractive. Since the stock market is only weakly correlated with his other risks, it diversifies those other risks and so the combination is attractive: even a loss averse agent enjoys diversification. As a result, he charges a low equity premium. To generate a large premium, we would need to push up aversion to overall wealth risk, but this would immediately lead to a violation of condition $\mathrm{L}$.

As we saw in Section 3.3, a simple way out of this difficulty is to argue that, when the agent evaluates stock market risk, he does not fully merge it with his other risks, but rather, evaluates it in isolation; in other words, that he frames stock market risk narrowly.

\section{Other Applications}

Barberis, Huang, and Thaler (2006) argue that the preferences in equation (14) can also address a portfolio puzzle that is closely related to the equity premium puzzle, namely the stock market participation puzzle: the fact that, even though stocks have a high mean return, many households have historically been unwilling to allocate any money to them. Mankiw and Zeldes (1991) report, for example, that in 1984, only $28 \%$ of households held any stock at all, and only $12 \%$ held more than $\$ 10,000$ in stock. Non-participation was not simply the result of not having any liquid assets. Even among households with more than $\$ 100,000$ in liquid assets, only $48 \%$ held stocks (see also Haliassos and Bertaut, 1995).

\footnotetext{
${ }^{14}$ Epstein and Zin (1990) and Epstein and Zin (2001) obtain comparable results. For example, in Table 5 of their paper, Epstein and Zin (2001) report that, for parameterizations of the preferences in (40)-(42) that match the historical equity premium, the representative agent may charge as much as $\$ 23,000$ to avoid the $\pm \$ 25,000$ bet. See also Bekaert, Hodrick, and Marshall (1997).
} 
One approach to this puzzle is to argue that there are transaction costs of investing in the stock market; another is to examine whether non-stockholders have background risk that is somewhat correlated with the stock market (Heaton and Lucas 1997, 2000, VissingJorgensen, 2002). A third approach is preference-based, and this is the one Barberis, Huang, and Thaler (2006) focus on. Specifically, they show that the preferences in equation (14) can generate stock market non-participation, and, mirroring the results for the equity premium, that they can do so for preference parameterizations that are reasonable, in other words, that make sensible predictions about attitudes to large-scale monetary gambles by, for example, satisfying condition L.

It is easy to see how the preferences in (14) generate non-participation: if the agent gets direct utility from fluctuations in the value of any stocks that he owns, and if he is loss averse over these fluctuations, he is naturally going to be averse to stock market risk, and may refuse to participate.

How is it that Barberis, Huang, and Thaler (2006) generate non-participation for reasonable parameter values? An agent who refuses to participate in the stock market is effectively refusing to take on a small amount of a risk that is, according to Heaton and Lucas' (2000) estimates, relatively uncorrelated with his other risks. To generate such attitudes at the same time as reasonable attitudes to large-scale gambles, we need preferences that generate moderate aversion to a small, weakly correlated risk - thereby leading to stock market non-participation - at the same time as moderate aversion to a large, independent risk, thereby satisfying condition L. As discussed in Section 3.3, the preferences in equation (14) can achieve exactly this.

Without narrow framing, it becomes much harder to find preference specifications that can generate non-participation for reasonable parameter values. In the absence of narrow framing, the agent decides whether to participate by mixing a small amount of stock market risk with his other risks and checking whether the combination is attractive. Since stock market risk is only weakly correlated with his other risks, it is diversifying, and so the combination is, quite generally, attractive. To prevent the agent from participating, we need to impose very high aversion to overall wealth risk, but this typically leads to implausible aversion to large-scale gambles and, in particular, to violations of condition L. This logic has been confirmed by Heaton and Lucas (2000), Haliassos and Hassapis (2001), and Barberis, Huang, and Thaler (2006), who consider a number of different specifications without narrow framing - including specifications that incorporate loss aversion - and find that all of them have trouble generating non-participation for reasonable parameter values. ${ }^{15}$

\footnotetext{
${ }^{15}$ An alternative preference-based approach to the stock market participation puzzle is based on ambiguity aversion (Epstein and Schneider, 2002). This approach has some similarities to the narrow framing approach, in that it works by inducing something akin to loss aversion over the stock market gamble itself.
} 


\section{$5 \quad$ Further Extensions}

\subsection{Dynamic aspects of loss aversion}

In equilibrium, the preferences in (5) and (14) can easily deliver a high equity premium and a low and stable risk-free rate, but they have a harder time matching the empirical volatility of returns. Under these preferences, the volatility of returns is typically very similar to the volatility of dividend growth, and therefore too low.

Barberis, Huang, and Santos (2001) show that incorporating dynamic aspects of loss aversion into the specification in (5) can help match the empirical volatility of returns. ${ }^{16}$ Drawing on a number of different experimental tests, Thaler and Johnson (1990) argue that the degree of loss aversion is not constant over time, but depends on prior gains and losses. In particular, they present evidence that losses are less painful than usual after prior gains, perhaps because those gains cushion any subsequent loss; and that losses after prior losses are more painful than usual, perhaps because people have only limited capacity for dealing with bad news.

Barberis, Huang, and Santos (2001) capture this evidence by making $\bar{v}(\cdot)$ in (5) a function not only of the current stock market return $R_{S, t+1}$ but also of prior gains and losses in the stock market. They then show that this raises the volatility of returns relative to the volatility of dividend growth: on good dividend news, the stock market goes up, giving the investor a cushion of prior gains and making him less sensitive to future losses; as a result, he perceives stocks to be less risky and discounts their future cash flows at a lower rate, thereby pushing prices still higher and raising the volatility of returns. The same mechanism also generates predictability in the time series: after prior gains, the investor perceives the stock market to be less risky and so pushes the price of stocks up relative to dividends; but from this point on, average returns will be lower, as the investor needs less compensation for the lower perceived risk. Price-dividend ratios therefore predict returns.

One attractive feature of this mechanism is that it preserves the low correlation of stock returns and consumption growth seen in the models of Section 3: since movements in the price-dividend ratio are driven by innovations to dividends, the correlation of stock returns and consumption growth is similar to the correlation of dividend growth and consumption growth, and is therefore low. This contrasts with other models of stock market volatility, such as that of Campbell and Cochrane (1999), in which movements in the price-dividend ratio are driven by innovations to consumption. These models inevitably predict a high correlation of stock returns and consumption growth.

\footnotetext{
${ }^{16} \mathrm{~A}$ similar analysis can be conducted with the specification in equation (14).
} 


\subsection{Other forms of narrow framing}

In the economy described in Section 3, there were only two risky assets: the stock market and a non-financial asset. There were therefore only a limited number of ways in which narrow framing could manifest itself. The investor could get direct utility from stock market fluctuations, direct utility from fluctuations in the value of the non-financial asset, or both. A more realistic model would allow the investor to trade not only a broad stock market index, but individual stocks as well. Narrow framing could then, in principle, mean that the investor gets direct utility from fluctuations in the value of individual stocks that he owns. What effect would this have?

Barberis and Huang (2001) investigate this issue by extending the preferences in (5) to allow the agent to frame several assets narrowly. ${ }^{17}$ Among other implications, they find that, if investors engage in the more extreme form of narrow framing whereby they frame even individual stocks narrowly, the equity premium can be even higher than in the case studied in Section 3, where they frame only their overall portfolio of stocks narrowly: if investors worry about fluctuations in highly volatile individual stocks rather than about fluctuations in the less volatile aggregate stock market, they perceive stocks to be very risky and charge a very high equity premium in equilibrium.

Is it plausible that people might frame individual stocks narrowly? From a theoretical perspective, it is hard to tell. Consider Kahneman's (2003) "accessibility" theory of framing. It is true that for most investors, information about the return distribution of individual stocks is highly accessible. But so too is information about the return distribution of diversified stock portfolios, and it seems that given a choice between the broader frame and the narrower one, people will choose the normatively more acceptable frame, namely the broader one, for their decision-making.

Under the alternative theory that narrow framing is related to non-consumption utility such as regret, framing at the level of individual stocks becomes more plausible. If one of the investor's stocks performs poorly, he may regret the specific decision to buy that stock. Gains and losses on individual stocks can therefore be carriers of utility in their own right, and the investor may take this into account when making decisions.

The framing of individual stocks is also supported by the well-known disposition effect the fact that, when individual investors sell stocks in their portfolios, they tend to sell stocks that have gone up in value since purchase, rather than stocks that have gone down in value (Shefrin and Statman, 1985, Odean, 1998). A common explanation for this finding is that people get direct utility from realizing a loss on an individual stock that they own and that this leads them to postpone selling a losing stock for as long as possible. ${ }^{18}$

\footnotetext{
${ }^{17} \mathrm{~A}$ similar analysis can be conducted with the specification in equation (14).

${ }^{18}$ Tax considerations point to the selling of prior losers, so they cannot explain the disposition effect. Nor
} 


\section{Conclusion and Future Directions}

In this essay, we review a recent approach to addressing the equity premium puzzle. The broad theme of this approach is that we may be able to improve our understanding of how people evaluate stock market risk by looking at how they evaluate risk in experimental settings. Specifically, this approach argues that loss aversion and narrow framing, two of the most important ideas to emerge from the experimental literature on decision-making under risk, may also play an important role in the way some people think about the stock market.

We discuss various ways of incorporating loss aversion and narrow framing into more traditional utility functions, and show that models with these features may indeed offer an attractive way of thinking about the historical equity premium. For example, they can generate a high equity premium and a low and stable risk-free rate, even when consumption growth is smooth and only weakly correlated with the stock market; moreover, they can do this for parameter values that are reasonable, in other words, parameter values that correspond to sensible attitudes to independent monetary gambles. A parallel result holds in the case of the stock market participation puzzle: loss aversion and narrow framing can generate non-participation for reasonable parameter values.

While these initial results are promising, much work remains. The most obvious direction for future research is to think about testable implications of the loss aversion / narrow framing view. For example, while narrow framing makes a blanket prediction of non-participation in the stock market, does it also make more detailed predictions about what kinds of people are more likely to participate than others? Does it predict changes in participation over time, perhaps due to changes in framing? Are there any real-world situations in which people are asked to make a certain financial decision after seeing some data, and that have the feature that while everyone sees the same data, some people see it presented somewhat differently than others? The differences in the way the data is presented could lead people to frame future outcomes differently, and therefore to make different choices.

Researchers have already begun testing the view of the equity premium and participation puzzles presented here. Dimmock (2005) describes a survey, conducted in the Netherlands, in which subjects were given a decision problem involving riskless choice. Responses to this decision problem can be used to extract estimates of individual loss aversion. After extracting these estimates from the data, Dimmock (2005) finds that individuals with greater loss aversion are indeed less likely to participate in the stock market.

Narrow framing is harder to measure than loss aversion, but successful tests of narrow framing in other settings suggest that progress can also be made in the context of the equity

can the effect be explained by a rational belief in mean-reversion: the stocks that individual investors sell actually outperform the ones they buy (Odean, 1998). 
premium and stock market participation puzzles. Kumar and Lim (2004), for example, test the idea that narrow framing is behind the disposition effect by checking whether individual investors who engage less in narrow framing also exhibit the disposition effect less. They identify these investors as those who tend to execute more than one trade on any given day, and who might therefore pay less attention to the outcome of any one transaction. They find that these investors do indeed exhibit less of a disposition effect.

Our attempt to bring psychology into economics has also served to highlight some areas of psychology where more research would be valuable. While there is evidence that, in some situations, people frame narrowly, we still do not fully understand when people frame narrowly and when they do not, nor what the underlying causes of narrow framing are. Similarly, while loss aversion itself is a robust and well-documented phenomenon, much less is known about its dynamic aspects: for example, about how past gains and losses affect subsequent loss aversion. Thaler and Johnson (1990) provide some valuable evidence on this point, but it is hard to believe that theirs is the last word. A better understanding of these issues, perhaps through more experimental research, may eventually help us craft better models of how people evaluate stock market risk. 


\section{$7 \quad$ References}

Ang, A., G. Bekaert, and J. Liu (2005), "Why Stocks May Disappoint," Journal of Financial Economics 76:471-508.

Barberis, N. and M. Huang (2001), "Mental Accounting, Loss Aversion, and Individual Stock Returns," Journal of Finance 56:1247-1292.

Barberis, N. and M. Huang (2004), "Preferences with Frames: A New Utility Specification that Allows for the Framing of Risks," Working paper, Yale University.

Barberis, N. and M. Huang (2005), "Stocks as Lotteries: The Implications of Probability Weighting for Security Prices," Working paper, Yale University.

Barberis, N., M. Huang, and T. Santos (2001), "Prospect Theory and Asset Prices," Quarterly Journal of Economics 116:1-53.

Barberis, N., M. Huang, and R. Thaler (2006), "Individual Preferences, Monetary Gambles, and Stock Market Participation: A Case for Narrow Framing," American Economic Review, forthcoming.

Barberis, N. and W. Xiong (2005), "What Drives the Disposition Effect? An Analysis of a Long-standing Preference-based Explanation," Working paper, Yale University.

Bekaert, G., R. Hodrick, and D. Marshall (1997), "The Implications of First-order Risk Aversion for Asset Market Risk Premiums," Journal of Monetary Economics 40:3-39.

Benartzi, S. and R. Thaler (1995), "Myopic Loss Aversion and the Equity Premium Puzzle," Quarterly Journal of Economics 110:75-92.

Campbell, J.Y. and J. Cochrane (1999), "By Force of Habit: A Consumption-based Explanation of Aggregate Stock Market Behavior," Journal of Political Economy 107:205-251.

Cicchetti C. and J. Dubin (1994), "A Microeconometric Analysis of Risk Aversion and the Decision to Self Insure," Journal of Political Economy 102:169-186.

Cohen, A. and L. Einav (2005), "Estimating Risk Preferences from Deductible Choice," Working paper, Stanford University.

Dimmock, S. (2005), "Loss Aversion and Household Portfolio Choice," Working paper, Michigan State University. 
Epstein, L. and M. Schneider (2002), "Learning Under Ambiguity," Working paper, University of Rochester.

Epstein, L. and S. Zin (1989), "Substitution, Risk Aversion, and the Temporal Behavior of Consumption and Asset Returns: A Theoretical Perspective," Econometrica 57, 937-969.

Epstein, L. and S. Zin (1990), "First-order Risk Aversion and the Equity Premium Puzzle," Journal of Monetary Economics 26:387-407.

Epstein, L. and S. Zin (2001), "The Independence Axiom and Asset Returns," Journal of Empirical Finance 8:537-572.

Gneezy, U. and J. Potters (1997), "An Experiment on Risk Taking and Evaluation Periods," Quarterly Journal of Economics 112:631-645.

Gomes, F. (2005), "Portfolio Choice and Trading Volume with Loss Averse Investors," Journal of Business 78:675-706.

Gul, F. (1991), "A Theory of Disappointment Aversion," Econometrica 59:667-686.

Haliassos, M. and C. Bertaut (1995), "Why Do So Few Hold Stocks?" Economic Journal 105:1110-1129.

Haliassos, M. and C. Hassapis (2001), "Non-expected Utility, Saving, and Portfolios," Economic Journal 111:69-102.

Heaton, J. and D. Lucas (1997), "Market Frictions, Savings Behavior, and Portfolio Choice," Macroeconomic Dynamics 1:76-101.

Heaton, J. and D. Lucas (2000), "Portfolio Choice in the Presence of Background Risk," Economic Journal 110:1-26.

Kahneman, D. (2003), "Maps of Bounded Rationality: Psychology for Behavioral Economics," American Economic Review 93:1449-1475.

Kahneman, D., A. Knetsch, and R. Thaler (1990), "Experimental Tests of the Endowment Effect and the Coase Theorem," Journal of Political Economy 98:1325-1348.

Kahneman, D. and D. Lovallo (1993), "Timid Choices and Bold Forecasts: A Cognitive Perspective on Risk Taking," Management Science 39:17-31.

Kahneman, D. and A. Tversky (1979), "Prospect Theory: An Analysis of Decision under Risk," Econometrica 47:263-291. 
Kahneman, D. and A. Tversky (1982), "The Psychology of Preferences," Scientific American 246:160-173.

Kahneman, D. and A. Tversky (1983), "Choices, Values, and Frames," American Psychologist 39:341-350.

Kandel, S. and R. Stambaugh (1991), "Asset Returns and Intertemporal Preferences," Journal of Monetary Economics 27:39-71.

Kumar, A. and S. Lim (2004), "One Trade at a Time: Narrow Framing and Stock Investment Decisions of Individual Investors," Working paper, University of Notre Dame.

Mankiw, N.G. and S. Zeldes (1991), "The Consumption of Stockholders and Non-stockholders," Journal of Financial Economics 29:97-112.

Mehra, R. and E. Prescott (1985), "The Equity Premium: A Puzzle," Journal of Monetary Economics 15:145-161.

Odean, T. (1998), "Are Investors Reluctant to Realize their Losses?" Journal of Finance 53:1775-1798.

Rabin, M. (2000), "Risk Aversion and Expected Utility Theory: A Calibration Theorem," Econometrica 68:1281-1292.

Rabin, M. and R. Thaler (2001), "Anomalies: Risk Aversion," Journal of Economic Perspectives 15:219-232.

Read, D., G. Loewenstein, and M. Rabin (1999), "Choice Bracketing," Journal of Risk and Uncertainty 19:171-197.

Redelmeier, D. and A. Tversky (1992), "On the Framing of Multiple Prospects," Psychological Science 3:191-193.

Shefrin, H. and M. Statman (1985), "The Disposition to Sell Winners too Early and Ride Losers too Long," Journal of Finance 40:777-790.

Thaler, R. (1980), "Towards a Positive Theory of Consumer Choice," Journal of Economic Behavior and Organization 1:39-60.

Thaler, R. and E. Johnson (1990), "Gambling with the House Money and Trying to Break Even: The Effects of Prior Outcomes on Risky Choice," Management Science 36:643-660.

Thaler, R., A. Tversky, D. Kahneman, and A. Schwartz (1997), "The Effect of Myopia and 
Loss Aversion on Risk Taking: An Experimental Test," Quarterly Journal of Economics 112:647-661.

Tversky, A. and D. Kahneman (1981), "The Framing of Decisions and the Psychology of Choice," Science 211:453-458.

Tversky, A. and D. Kahneman (1986), "Rational Choice and the Framing of Decisions," Journal of Business 59:5251-78.

Tversky, A. and D. Kahneman (1992), "Advances in Prospect Theory: Cumulative Representation of Uncertainty," Journal of Risk and Uncertainty 5:297-323.

Vissing-Jorgensen, A. (2002), "Towards an Explanation of Household Portfolio Choice Heterogeneity: Nonfinancial Income and Participation Cost Structures," Working paper, Northwestern University. 
Table 1: Parameter values for a representative agent equilibrium model: $g_{C}$ and $\sigma_{C}$ are the mean and standard deviation of log consumption growth, $\sigma_{S}$ is the standard deviation of log stock returns, and $\rho_{C S}$ is the correlation of log consumption growth and $\log$ stock returns.

\begin{tabular}{ll}
\hline Parameter & \\
\hline$g_{C}$ & $1.84 \%$ \\
$\sigma_{C}$ & $3.79 \%$ \\
$\sigma_{S}$ & $20.0 \%$ \\
$\rho_{C S}$ & 0.10 \\
\hline
\end{tabular}


Table 2: The table shows, for given aversion to consumption risk $\gamma$, sensitivity to narrowly framed losses $\lambda$, and degree of narrow framing $b_{0}$, the risk-free rate $R_{f}$ and equity premium EP generated by narrow framing in a simple representative agent economy. $\pi_{L}$ is the premium the representative agent would pay, given his equilibrium holdings of risky assets and wealth of $\$ 75,000$, to avoid a 50:50 bet to win or lose $\$ 25,000$.

\begin{tabular}{rrrrrr}
\hline$\gamma$ & $\lambda$ & $b_{0}$ & $R_{f}$ & $\mathrm{EP}$ & $\pi_{L}$ \\
\hline 1.5 & 2 & 0 & $4.7 \%$ & $0.12 \%$ & $\$ 6,371$ \\
1.5 & 2 & 0.05 & $3.7 \%$ & $3.72 \%$ & $\$ 6,285$ \\
1.5 & 2 & 0.1 & $3.4 \%$ & $4.63 \%$ & $\$ 6,269$ \\
1.5 & 3 & 0 & $4.7 \%$ & $0.12 \%$ & $\$ 6,371$ \\
1.5 & 3 & 0.05 & $2.7 \%$ & $7.00 \%$ & $\$ 8,027$ \\
1.5 & 3 & 0.1 & $2.3 \%$ & $8.12 \%$ & $\$ 8,188$ \\
3 & 2 & 0 & $7.1 \%$ & $0.24 \%$ & $\$ 11,754$ \\
3 & 2 & 0.05 & $5.3 \%$ & $3.29 \%$ & $\$ 8,318$ \\
3 & 2 & 0.1 & $4.7 \%$ & $4.37 \%$ & $\$ 7,383$ \\
3 & 3 & 0 & $7.1 \%$ & $0.24 \%$ & $\$ 11,754$ \\
3 & 3 & 0.05 & $3.3 \%$ & $6.65 \%$ & $\$ 8,981$ \\
3 & 3 & 0.1 & $2.4 \%$ & $8.08 \%$ & $\$ 8,601$ \\
\hline
\end{tabular}


Table 3: The table shows, for given aversion to consumption risk $\gamma$, sensitivity to narrowly framed losses $\lambda$, and degree of narrow framing $b_{0}$, the risk-free rate $R_{f}$ and equity premium EP generated by narrow framing in a simple representative agent economy. $\pi_{L}$ is the premium the representative agent would pay, given his equilibrium holdings of risky assets and wealth of $\$ 75,000$, to avoid a $50: 50$ bet to win or lose $\$ 25,000 . T$ is the interval, in years, over which stock market gains and losses are measured.

\begin{tabular}{rrrrrrr}
\hline$T$ & $\gamma$ & $\lambda$ & $b_{0}$ & $R_{f}$ & $\mathrm{EP}$ & $\pi_{L}$ \\
\hline 0.5 & 1.5 & 2 & 0.1 & $2.5 \%$ & $7.59 \%$ & $\$ 6,257$ \\
1 & 1.5 & 2 & 0.1 & $3.4 \%$ & $4.63 \%$ & $\$ 6,269$ \\
2 & 1.5 & 2 & 0.1 & $4.0 \%$ & $2.53 \%$ & $\$ 6,288$ \\
3 & 1.5 & 2 & 0.1 & $4.3 \%$ & $1.70 \%$ & $\$ 6,301$ \\
\hline
\end{tabular}

Table 4: The table shows, for given aversion to consumption risk $\gamma$, sensitivity to narrowly framed losses $\lambda$, and degree of narrow framing $b_{0}$, the risk-free rate $R_{f}$ and equity premium EP generated by narrow framing in a simple representative agent economy. $\pi_{L}\left(\pi_{S}\right)$ is the premium the representative agent would pay, given his equilibrium holdings of risky assets and wealth of $\$ 75,000$, to avoid a 50:50 bet to win or lose $\$ 25,000$ ( $\$ 250$ ).

\begin{tabular}{rrrrrrr}
\hline$\gamma$ & $\lambda$ & $b_{0}$ & $R_{f}$ & $\mathrm{EP}$ & $\pi_{L}$ & $\pi_{S}$ \\
\hline 1.5 & 2 & 0.035 & $3.8 \%$ & $3.14 \%$ & $\$ 6,297$ & $\$ 38.7$ \\
1.5 & 3 & 0.012 & $3.8 \%$ & $3.06 \%$ & $\$ 7,252$ & $\$ 37.7$ \\
3 & 2 & 0.050 & $5.3 \%$ & $3.29 \%$ & $\$ 8,318$ & $\$ 39.5$ \\
3 & 3 & 0.016 & $5.4 \%$ & $3.10 \%$ & $\$ 10,259$ & $\$ 37.1$ \\
\hline
\end{tabular}




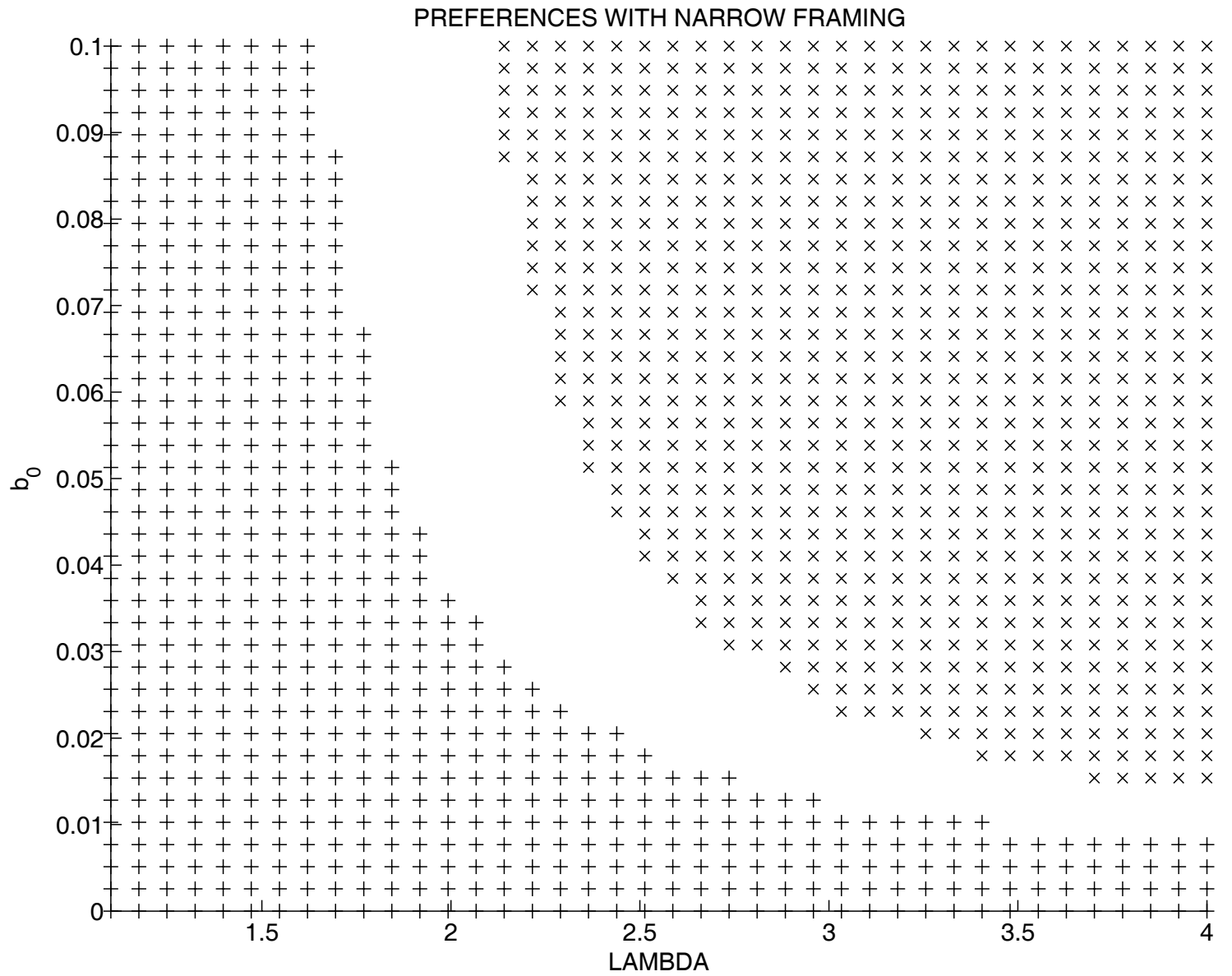

Figure 1. The " $\mathrm{x}$ " signs mark the parameter values for which an agent who is loss averse over stock market risk would charge an equity premium higher than 5\% in a simple representative agent economy. The "+" signs mark the parameter values for which the agent would pay a premium below $\$ 40$ to avoid a 50:50 bet to win or lose $\$ 250$ at a wealth level of $\$ 75,000$. 


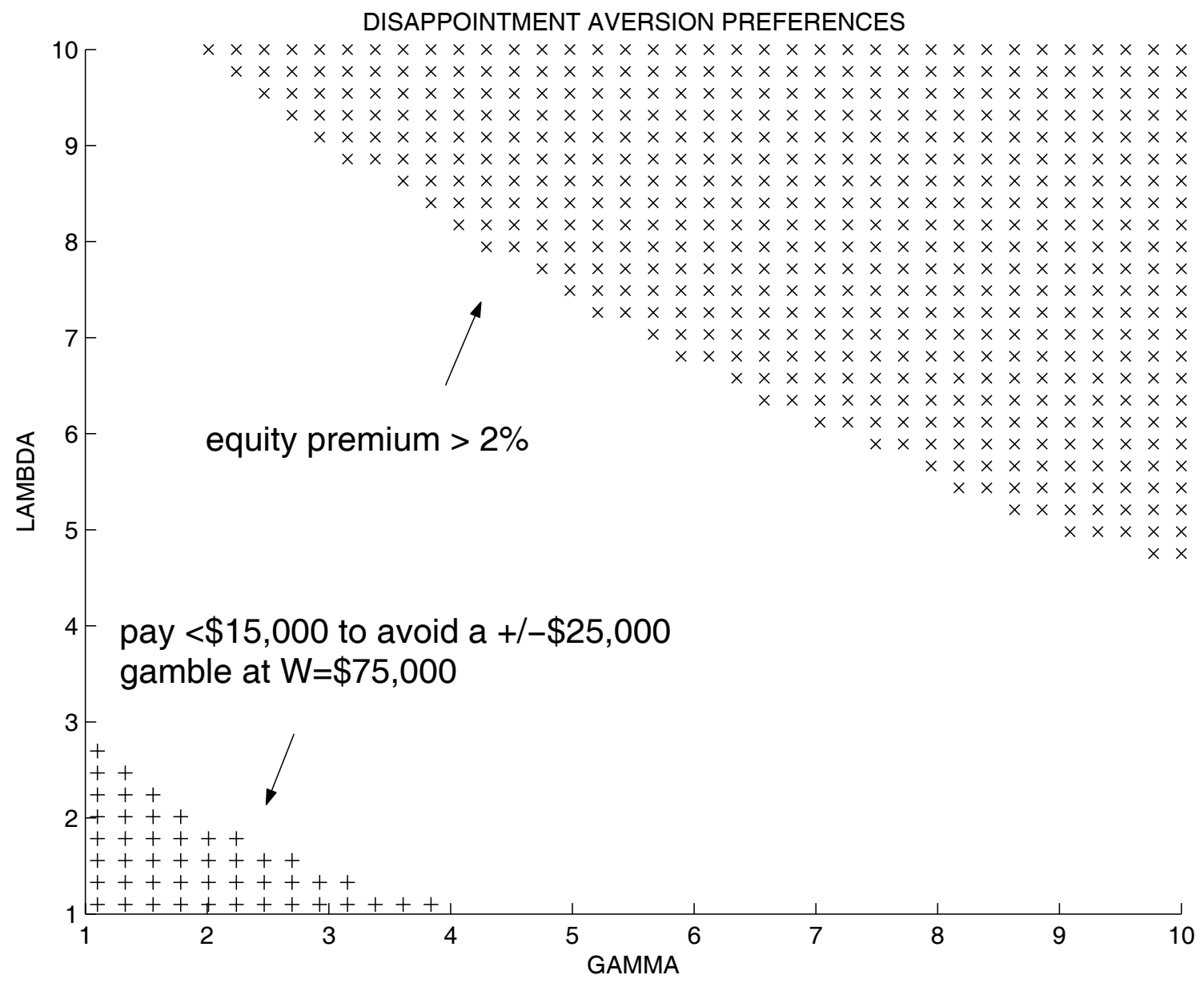

Figure 2. The " $x$ " signs mark the parameter values for which an agent with a recursive utility function with Gul (1991)-type certainty equivalent would charge an equity premium higher than $2 \%$ in a simple representative agent economy. The "+" signs mark the parameter values for which the agent would pay a premium below $\$ 15,000$ to avoid a $50: 50$ bet to win or lose $\$ 25,000$ at a wealth level of $\$ 75,000$. 